\title{
A MORADIA EM UBERLÂNDIA
}

\author{
Beatriz Ribeiro Soares \\ Profa. Dra. do Dep. de Geografia - UFU \\ Luiz G. Falcão Vasconcellos \\ Prof. do Dep. de Geografia - UFU
}

RESUMO: Este trabalho, apresentado no encontro "A moradia em Uberlândia" no dia 28 de março de 1993, promovido pelo Centro de Defesa dos Direitos Humanos de Uberlândia, faz parte de um projeto no qual seus integrantes vêm discutindo e refletindo sobre o desenvolvimento urbano das cidades brasileiras como um todo e, em especial, a cidade de Uberlândia. Nesse sentido, buscamos entender o processo de crescimento urbano da cidade, partindo da questão da moradia, desde os anos 50 até os dias atuais, sua dinâmica, seus programas institucionais e seus problemas.

Palavras Chaves: moradia, condições de vida, problemas urbanos

ABSTRACT: This paper, presented at the meeting "Housing in Uberlandia"in March/28/93, promoted by "Centro de Defesa dos Direitos Humanos de Uberlândia" (Uberlândia Human Rights Deffence Center), is part of a major project about the urban development in brasilian cities, specially Uberlandia. We deal with the urban process of the city development, questions of housing, from the 50's to today, its dinamics, its institucional programs and its problems.

Key Words: housing, living conditions, urban problems.

\section{CONSIDERAÇÕES INICIAIS}

Para um adequado entendimento dos problemas da habitação na cidade, é preciso buscar-se em primeiro lugar um melhor conhecimento em termos da complexidade da vida urbana. Cidades do mesmo porte populacional que Uberlândia têm tido, desde os anos 60 , um crescimento demográfico muito superior ao crescimento de seus domicílios. Além disto os anos 80 trouxeram, com a recessão, a pauperização acelerada e uma violenta redução dos investimentos, tanto públicos como privados, em obras de urbanização, construção civil, especialmente aquelas voltadas para as camadas populares das cidades médias brasileiras.

Contraditoriamente, nesse quadro, a população urbana passou ainda, no final da década de 80 , a representar $75 \%$ da população total do País.

Nas cidades, a imensa maioria dos citadinos passa mais e mais à condição de miserável, vendo-se crescentemente privados da mais elementar condição de vida, com pouca ou nentuma perspectiva. Excluídos do mercado de consumo e da "cidade legal", esses habitantes vêem-se forçados a saídas para a sobrevivência:

- Cresce o número de habitantes das favelas e seus limites se expandem;

- Os terrenos ociosos e muitíssimas vezes especulativos são "ocupados" (invadidos?);

- O mercado de lotes em situação irregular e mais barato se intensifica;

- Cresce a procura por cortiços, casas de cômodos, etc.. (para aluguel);

- Aumentam as construções em beiras de córregos, rios, encostas, áreas de risco em geral e até em áreas de preservação.

Nessas condições os problemas se avolumam, as próprias populações são atingidas, e a cidade como um todo também.

A natureza, sendo inadequadamente utilizada, tende a se rearrumar, e com isto suas 
forças podem, no caso da cidade, colocar em situação vulnerável, por exemplo, seu arruamento e suas vias de circulação.

Por outro lado, tornam-se mais precárias as condições de salubridade no espaço urbano, agudizando-se muitas vezes, com os riscos sempre crescendo.

No âmbito do planejamento, os esforços frustram-se, na maioria das vezes, inclusive pela ineficiência da adoção de modelos e do equívoco das "soluções" correntes de "desenvolvimento urbano".

As situações de conflito acirram-se, ampliando-se rapidamente, passando a cidade a conviver permanentemente com litígios relacionados ao acesso à terra/habitação, onde os despejos, as remoções e a violência policial passam a acontecer cada vez mais rotineiramente.

Consideramos que não é adequado buscar a análise desse quadro partindo da ótica de "carência" ou "ausência", como costuma acontecer, ou seja, do consumo frustrado. Necessário se faz desnudar, colocar às claras os mecanismos que levam a esta situação. Para entender o "por quê" da pobreza é preciso conhecer como se acumula a riqueza, no caso, dentro do espaço da cidade. É preciso conhecer como se dá a produção na/ e da cidade.

Não se pode discutir o consumo ou a sua ausência sem tratar da produção. No contexto amplo da produção de mercadorias em nossa sociedade, inclui-se a produção de um tipo de espaço urbano que reproduz a pobreza, não como carência, mas como parte integrante de uma lógica que mais e mais intensamente vem transformando a cidade num imenso e sofisticado supermercado, onde uma das mercadorias mais caras de consumo privado, a habitação, um bem especial, de produção e distribuição complexas, torna-se cada vez menos acessível para a maioria dos seus habitantes. Porisso fala-se hoje, no Brasil, que possivelmente 10 milhões de pessoas morem na rua e vivam a perambular pelos logradouros de suas cidades.

A habitação na sociedade capitalista é considerada como um dos elementos essenciais à reprodução da força de trabalho, enquanto abrigo, local de reposição do desgaste físico e de satisfação das necessidades de natureza física, social e cultural dos trabalhadores. Nesse sentido a moradia, compreendida na esfera do consumo, tem um valor de uso. No entanto, tem também um valor de troca, na medida em que se transforma em mercadoria, tendo desta forma um preço que depende das regras e condições do mercado.

Só para se ficar nos determinantes específicos da realidade urbana brasileira, façamos um exercício, olhemos para nossa cidade, para dentro dela. As diferenciações não acontecem somente nos espaços privados, mas também nos espaços públicos e, quase que invariavelmente, de maneira muito clara. Destaque-se que a diversidade de situações na cidade não vai se relacionar com o tempo de ocupação de seus bairros ou áreas. É bastante fácil intentificarem-se áreas "bem localizadas", servidas de toda infra-estrutura e tratamento privilegiado por parte do Poder Público, embora tenham pouca ou nenhuma ocupação humana. Por outro lado, em outros bairros ou áreas, inclusive de ocupação mais antiga, com centenas e milhares de famílias, encontra-se quando muito uma infra-estrutura mínima, na maioria das vezes precária e com baixíssima atenção por parte do Poder Público.

O elevado e sempre crescente preço da terra urbana, ao lado do baixo e sempre achatado poder aquisitivo de amplas parcelas da população, funciona como forte fator de exclusão do direito à cidade, impedindo o acesso à habitação/moradia, mesmo em uma cidade onde "existe muita terra para pouca gente", como é o caso de Uberlândia.

\section{UBERLÂNDIA: ONDE MORAS?}

1.1. Os planos habitacionais federais: da Fundação Casa Popular ao Banco Nacional de Habitação $\mathrm{BNH}$

Em Uberlândia, a produção de moradias, principalmente aquela voltada para as classes trabalhadoras, sempre esteve vinculada a programas institucionais, fossem eles municipais, estaduais ou federais. Em nível local, os planos habitacionais têm servido para atender determinados interesses político-partidários, bem como propiciar novos empregos na construção civil e incrementar a indústria de materiais de construção. 
A Fundação Casa Popular, as Caixas Econômicas Estadual e Federal, o Banco Nacional de Habitação, os Institutos de Previdência e Aposentadorias, a Prefeitura Municipal de Uberlândia construíram e financiaram, a partir da década de 50 até os dias atuais, aproximadamente 30 mil casas para a população assalariada de Uberlândia.

Entretanto, ficaram de fora desses planos os trabalhadores que não podiam comprovar renda ou salário exigidos pelos mesmos, e desta maneira viram-se obrigados a encontrar alternativas de produção de moradias. Dentre elas podemos citar os cortiços e a autoconstrução.

Os anos 40 marcaram o início da participação do Estado na produção e comercialização de habitação popular no Brasil, com a criação a nível federal da Fundação Casa Popular. Por seu intermédio foram construídos dois conjuntos habitacionais, com 130 casas em Uberlândia, na década de 1950 . O primeiro, com 50 casas, foi entregue em 1954 e o segundo, com 80 casas, em 1961. Os dois conjuntos, construídos em áreas ainda não habitadas, vieram aumentar os custos da urbanização, além de contribuir para a expansão da cidade nas direções norte e sul.

Os candidatos a essas moradias tinham que ser brasileiros, casados, e não possuir casa própria. A prestação era calculada de acordo com a idade, e tinham isenção de impostos municipais e federais durante todo o período de financiamento da casa. A Fundação Casa Popular também fazia exigências no que diz respeito à vida dos moradores, principalmente quanto a questões de ordem higiênica e moral, além de não poder a casa ser utilizada para nenhuma atividade de cunho político, religioso ou recreativo.

Com a expansão da cidade na década de 60 , frente à intensificação do comércio e implantação da Cidade Industrial, vários problemas ocorreram, particularmente os ligados à questão da moradia: aumento de preço dos aluguéis, proliferação de favelas, enfim, ampliação das dificuldades quanto ao acesso à moradia.

Foram viabilizadas propostas para construção de casas, via Institutos de Previdência e Aposentadoria, como por exemplo o dos bancários e industriários, que construíram moradias com base na Lei Orgânica da Previdência Social, a qual previa programas de construção de moradias para os segurados dos referidos institutos. Por essa via foram construídos conjuntos e casas para esses trabalhadores em Uberlândia, dentre os quais podemos citar o Conjunto dos Bancários, no Bairro Martins.

Com o advento do regime militar, ao lado da crise econômico/social brasileira, em meados da década de 60 , foi implantada uma nova política habitacional de âmbito nacional, sendo por esse meio criado o Banco Nacional de Habitação - BNH, em 02 de agosto de 1964, pela Lei no. 4380. Esse banco recebeu as funções de órgão gestor e agente executivo do Sistema Financeiro de Habitação $\mathrm{SFH}$, com a competência de: orientar, disciplinar e controlar o Sistema Financeiro da Habitação e promover a construção e aquisição da casa própria, especialmente para as classes de menor renda.

Essa política foi orientada pela lógica empresarial, ocasionando o retorno dos investimentos em forma de lucro. Estabeleceu-se assim uma contradição, uma ambivalência na dinâmica do BNH: criado para atender objetivos sociais, utilizou mecanismos empresariais, articulando os setores público e privado.

A criação do BNH estabeleceu um momento institucional muito peculiar no encaminhamento da política habitacional brasileira, pois mesmo em se tratando de um banco com objetivos sociais, operava com normas do sistema capitalista em termos de retorno de investimentos. Adotou-se a correção monetária nos constratos de financiamento, com o objetivo de compensar a desvalorização do dinheiro pela inflação.

A captação de recursos foi viabilizada pela poupança compulsória, através do Fundo de Garantia por Tempo de Serviço - FGTS, e pelas cadernetas de poupança e letras imobiliárias.

Em relação ao financiamento de moradias, - BNH definiu agentes específicos para cada segmento do mercado, assim divididos: a) mercado popular, atendido pelas companhias habitacionais - COHAB's - para famílias com rendas entre um e três salários mínimos; b) mercado econômico, atendido pelas cooperativas habitacionais, órgãos sem fins lucrativos, formado por categorias profissionais sob a forma de condomínios. Estas 
eram as intermediárias entre o $\mathrm{BNH}$ e o mutuário. Esse mercado atendia famílias com rendas entre três e seis salários mínimos; c) mercado médio, atendido essencialmente pelos agentes privados a partir das sociedades de crédito imobiliário, associações de poupança e empréstimo, além das Caixas Econômicas. Essas instituições formavam - Sistema Brasileiro de Poupança e Empréstimo SBPE, e estavam voltadas, principalmente, para o atendimento das classes médias, e também para os setores que demandavam construções de luxo, com rendas superiores a seis salários mínimos.

De 1964 a 1980 o BNH financiou um milhão de casas para o mercado popular e 1,8 milhão para os mercados médio ou de luxo. O poder de ação do BNH foi tão forte que moldou a própria política urbana, uma vez que redefiniu os processos de "morar e viver" nas cidades brasileiras. Isto ocoreu, ainda que o seu desempenho social tivesse um saldo quantitativo irrisório na produção de moradia para população de baixa renda. $O$ entendimento do processo de desenvolvimento urbano no Brasil desse período passa necessariamente pelo conhecimento da ação do $\mathrm{BNH}$ e de suas formas de atuação.

A presença do $\mathrm{BNH}$ em Uberlândia foi significativa no que diz respeito à produção de moradias para os trabalhadores associados, entre os anos 1968/86. Por seu meio foram construídas aproximadamente 10 mil casas em conjuntos habitacionais com mais de 60 unidades residenciais, através das COHAB's, Cooperativas Habitacionais e do Sistema Brasileiro de Poupança e Empréstimo - SBPE.

$\mathrm{Na}$ cidade, o BNH começou a financiar/ produzir moradias a partir de 1968 , quando a $\mathrm{COHAB}$ construiu 300 casas no Bairro Industrial. Ali foi implantado um novo padrão de habitação, em 200 mil m2 e a $7 \mathrm{Km}$ do centro da cidade em linha reta, com casas unifamiliares, onde as atividades de lazer, religiosas, de ensino e de comércio eram segregadas espacialmente.

Em termos de produção de moradia para o mercado popular, a Prefeitura escolhia o terreno e comercializava as habitações; a COHAB comprava o terreno, financiava e fiscalizava a obra. Por esse processo foram construídos os seguintes conjuntos: Industrial, com 300 casas; Luizote de Freitas, com 4.032 casas; Segismundo Pereira, com 1.055 e Santa Luzia, com 799.
Esses conjuntos foram construídos em descontinuidade com a malha urbana, existindo grandes áreas desabitadas em seu entorno, contribuindo com a especulação imobiliária. De outro modo foram criadas novas áreas, com espaços específicos para lazer, escola, consumo, saúde, etc., pelo fato de que nelas passou a morar um contingente significativo da força de trabalho assalariada da cidade, constituindo dessa forma um novo urbano.

Com relação ao mercado econômico, as cooperativas habitacionais - Cruzeiro do Sul, Carajás, Bandeirantes - construíram casas e apartamentos em diversos bairros da cidade. Dentre eles podemos citar: conjunto Mona Lisa, no bairro Roosevelt; conjunto Higino Guerra, no bairro Martins; Cruzeiro do Sul, no bairro Marta Helena.

Através do mercado médio foram construídos diversos conjuntos, tanto para trabalhadores de renda de 3 a 5 salários mínimos conjunto Alvorada, Satélite, como para rendas maiores - conjunto Umuarama. Nesse processo encontramos uma diversidade grande na produção de moradias, com diferenças gritantes no que diz respeito à qualidade da construção, instalação de equipamentos públicos e infra-estrutura.

O BNH foi extinto em novembro de 1986, e em sua trajetória a questão da habitação foi tratada sob a ótica de um empreendimento lucrativo, em moldes empresariais e desconsiderando o cunho social da mesma. Sob o prisma social, essa trajetória teve um efeito perverso, pois o Banco, concebido para em sua atuação atenuar as desigualdades sociais, termina por acentuá-las ainda mais, contribuindo para agravar a concentração de renda no País.

\section{2. - AUTOCONSTRUÇÃO: OUTRA FORMA DE MORAR NA CIDADE}

A partir da década de 70 , Uberlândia conheceu um crescimento urbano acelerado que levou à expansão das periferias, tanto sociais como físicas, transformando mais e mais a cidade em termos de segregação espacial e social. Diante desse quadro, os trabalhadores excluídos das políticas habitacionais vigentes encontraram alternativas para sua sobrevivência na autoconstrução, no cortiço e na favela. 
A autoconstrução é um processo pelo qual o trabalhador e sua família constróem suas casas, em terrenos próprios, particularmente, nos finais de semana. Isto se constitui em sobretrabalho, na medida que a moradia é produzida por trabalho não pago, uma vez que o salário deveria ser suficiente também para as despesas de moradia, o que contribui ainda mais para a exploração da força de trabalho. O processo de autoconstrução é de longa duração, realizado por etapas descontínuas, em geral nos loteamentos distantes das áreas centrais da cidade, sendo que a casa, no caso um bem em permanente construção, possibilita ao trabalhador o encaminhamento, ao menos em parte, do problema da moradia.

Em Uberlândia, a partir da década de 70 , com a expansão dos loteamentos periféricos, a autoconstrução se torna uma prática corrente para as classes trabalhadoras, em bairros como, por exemplo, Aclimação, Maravilha, Jardim das Plameiras, Santo Inácio, Planalto, Nossa Senhora das Graças, entre outros.

Esse processo se intensifica nos anos 80 em decorrência da conjuntura econômica brasileira. Em função disto, nos loteamentos onde a autoconstrução é uma realidade, as casas geralmente não estão concluídas, suas condições de habitabilidade são em geral inadequadas, e é frequente o congestionamento habitacional, ou seja, a área construída é muito pequena em relação ao número de moradores, e a quantidade de casas edificadas em um mesmo terreno costuma ser grande.

\section{3. - A FAVELA E A PREFEITURA MUNICIPAL}

Muito semelhante ao processo de autoconstrução em loteamentos periféricos, foi realizado pela Prefeitura - gestão 83/88 - um programa municipal de habitação para populações de baixa renda, cujo real objetivo era erradicar as favelas da cidade.

A existência de favelas - ocupação ilegal, submoradias, ausência de infra-estrutura básica em Uberlândia não constitui um fenômeno recente. $\mathrm{Na}$ década de 40, a imprensa uberlandense já colocava a favela como um dos problemas sociais da cidade. Tal problemática agravou-se bastante após a década de 70 , com a expansão da economia centrada na industrialização e nas transformações das relações capitalistas no campo.

As estatísticas da Prefeitura relativas a 1983 apontam que existiam em Uberlândia 2554 famílias morando em favelas nos seguintes locais da cidade: Leão XIII, Marta Helena, Rondon Pacheco, Jardim Brasília, Maravilha e Uberabinha. Essa famílias ocupavam ilegalmente terrenos públicos ao longo dos rios, ferrovias ou rodovias, e construíram suas moradias com restos de materiais de construção, madeira, plástico, etc.

Diante de tal situação, a Prefeitura de Uberlândia desenvolveu um programa municipal de habitação, na década de 80 , voltado para a população não atingida pelo Sistema Financeiro de Habitação - SFH e também, como já dissemos, visando a erradicação das favelas da cidade. Foram construídas, até 1988, 1770 unidades residenciais, pelo sistema de mutirão, nos bairros Esperança, Leão XIII, Tocantins, etc. O programa previa a construção de casas de $30 \mathrm{~m}^{2}$, financiadas pelo prazo de cinco anos pela Empresa de Construções e Obras Populares - EMCOP, com prestação equivalente a $10 \%$ da renda familiar.

\section{4. - A MORADIA EM UBERLÂNDIA NA ATUALIDADE: DA CAIXA ECONÔMICA FEDERAL À EMCOP}

A questão da habitação popular em Uberlândia, apesar de todos os programas implantados desde os anos 50 aos dias atuais, temse acirrado cada vez mais. A imprensa veicula cotidianamente o assunto, seja ele em relação à carência de habitação, ao valor da prestação, à qualidade e tamanho da moradia. Vale lembrar que o essencial da questão passa por outro viés, o salário, a condição de vida da população, que a cada dia piora para a maioria, e as soluções apresentadas apenas mascaram a realidade, uma vez que o fundo da questão é de ordem estrutural.

Atualmente as estatísticas veiculadas pela imprensa apontam um "déficit habitacional" próximo de 10.000 moradias na cidade, ao mesmo tempo em que a EMCOP diz estar construindo 10.100 unidades residenciais em Uberlândia, tendo entregue 4.350 (informações de março de 1993). Apenas nos conjuntos Santa Mônica II, Guarani, Parque das Laranjeiras e Mansour, anunciam-se 
8.000 casas. No entanto, é preciso dizer que essas casas, que têm entre 23 a $34 \mathrm{~m}^{2}$ de área construída, são entregues semi-prontas, com uma péssima qualidade habitacional, seja quanto aos materiais utilizados, salubridade, construção ou acabamento.

O financiamento é feito pela Caixa Econômica Federal em 25 anos, para trabalhadores com renda a partir de 2,5 salários mínimos, incluindo os valores do terreno, construção da moradia e ligações de água, energia elétrica e esgoto. As prestações têm um valor alto, e correspondiam em média a setecentos mil cruzeiros, no mês de março de 1993, corrigidas pela Taxa Referencial - TR mensal.

Segundo informações coletadas no Banco Integrado de Dados - BID - Uberlândia, entre os anos de 1983 e 1992 o número de unidades residenciais construídas foi da ordem de 14.875 , conforme o quadro a seguir.
Os que ficaram fora desse processo moram atualmente nas ruas da cidade, nas favelas, nas casas inacabadas, ou ainda pagando altos preços por aluguéis em cômodos ou casas de periferia.

A questão moradia na cidade deve ser encarada no sentido amplo, ou seja, a produção da casa, provisão de equipamentos urbanos, a qualidade da habitação, enfim, as condições de vida do trabalhador e sua família. Se pensarmos apenas nas estatísticas oferecidas pelo Poder Público, pela iniciativa privada e por outras instituições quanto à questão, correremos o risco de deixar fora de nossa análise o essencial, a qualidade de vida urbana na sociedade atual.

O cenário muito mais amplo, que em parte foi descrito e discutido neste trabalho, somente será alterado se houver uma elaboração coletiva de conhecimentos sobre Uberlândia, buscando-se a construção de caminhos e alternativas que levem

\section{DISTRIBUIÇÃO DAS UNIDADES HABITACIONAIS 1983/1992}

\begin{tabular}{|l|l|l|l|l|}
\hline \multicolumn{5}{|c|}{$\begin{array}{c}\text { UNIDADES SISTEMA PLANO } \\
83 / 88 \\
89 / 92 \text { ATE DEZ/92 }\end{array}$} \\
\hline SISTEMA & PLANO & ENTREGUES & A ENTREGAR & TOTAL \\
\hline CEF & PAIH & 4.906 & 6.449 & 11.355 \\
CEP & PEP & 778 & -778 \\
CEF & PLEMB & 302 & - & 710 \\
CEF & PROHAP & 850 & - & 850 \\
SFH & BNH & 792 & 192 & 192 \\
& & 6.942 & 6.641 & 990 \\
\hline TOTAL & 1.292 & & & 14.875 \\
\hline
\end{tabular}

Fonte: Banco Integrado de Dados - PMU/UDI-ACIUB-UFU

\section{UNIDADES SISTEMA PLANO}

Não podemos deixar de destacar que a grande maioria das mesmas se enquadra nas condições descritas anteriormente, além do que na prática não tem havido nenhum compromisso, seja por parte dos empreendedores, dos financiadores e do Poder Público no que diz respeito à urbanização, transportes, comunicação e outros requisitos necessários, particularmente o que estabelece o Artigo 135- Capítulo IV da Habitação, Título IV da Ordem Econômica - da Lei Orgânica Municipal.

\section{CONSIDERAÇÕES FINAIS}

Os conjuntos habitacionais construídos desde a década de 1960 vêm abrigando parte significativa da população assalariada da cidade. Dados os critérios definidores de suas liocalizações têm surgido, em geral, problemas sérios para seus habitantes e toda a coletividade, uma vez que os mesmos têm sido construídos muito distantes das áreas anteriormente habitadas, aumentando os custos da urbanização, incentivando a especulação imobiliária e reforçando a segregação espacial e social. 
à superação da realidade aqui apresentada, no embate dos contrários e na necessária e inadiável negociação da Reforma Urbana e de um Estatuto Jurídico para a cidade/município que venha ao encontro dos direitos e compromissos de todos os munícipes como instrumento básico de realização dos cidadãos, da cidadania..

\section{BIBLIOGRAFIA}

ANDRADE, L.A.G. Política urbanas no Brasil. O paradigma, a organização e a política. Estudos CEBRAP. (18):117-148, São Paulo, 1976.

AZEVEDO, S. Política de habitação popular e subdesenvolvimento. DINIZ, E. Políticas Públicas para Áreas Urbanas. Rio de Janeiro, Zahar, 1982, p.67-114.

AZEVEDO, S. e ANDRADE, L.A.G. Habitação e Poder, Rio de Janeiro, Zahar, 1982.

BOLAFFI, G. A casa das ilusões perdidas: aspectos sócio-econômicos do Plano Nacional de Habitação. Cadernos do CEBRAP, São Paulo, 1977.

KOWARICK, L. Exploração e reprodução da força de trabalho: o problema da casa no Brasil. In: PRADILLA, (org.) Ensayos sobre el problema de la vivenda en América Latina. México, Universidad Autonoma Metropolitana Xochimilco, 1982, p. 213-232

LEFEBVRE. H. O direito à cidade. São Paulo, Urupês, 1969

MARICATO E. (org.) A produção capitalista de casa (e da cidade) no Brasil Industrial. São Paulo, Alfa-Ômega, 1979.

Política habitacional no regime militar. Petrópolis, Vozes, 1987

PREFEITURA Municipal de Uberlândia. Banco de Dados Integrados - Uberlândia, 1992 - Os números do desenvolvimento. Uberlândia, 1992.

SOARES, B.R. Habitação e Produção do Espaço em Uberlândia. Dissertação de Mestrado, São Paulo, FFCLH/USP, 1988.

VALLADARES, L.P. Habitação em questão, Rio de Janeiro, Zaharm 1981.

Repensando a habitação no

Brasil, Rio de Janeiro, Zahar, 1983 